among Canadians with AS has not previously been examined, using data from a large clinical registry.

Objectives: To estimate the prevalence of EAMs, including uveitis, inflammatory bowel disease (IBD), dactylitis, and enthesitis, in a population of Canadians undergoing active management for AS.

Methods: This retrospective study used RHUMADATA ${ }^{\circledR}$, a multicentre registry developed by rheumatologists of the IRRM and Centre d'ostéoporose et de rhumatologie de Québec to evaluate the effectiveness and safety of rheumatologic therapies. Up to 15 years of real-world observational data on the broad set of patients treated in clinical practice are available. The proportion with EAMs was estimated according to type. The frequency of EAMs was compared according to age at cohort entry ( $\leq 40$ vs $>40$ years), sex, AS severity (by BASDAI score), and status of treatment with anti-TNFs (anti-TNF-naive, anti-TNF treated [without switching], and anti-TNF treated [with switching]).

Results: The mean (SD) age at cohort entry was 36.0 (12.6) years, and $60.0 \%$ were male. Of the 944 patients, $268(28.4 \%)$ were ever diagnosed with an EAM over a median of $9.66(10.58)$ years of follow-up. Prevalence was $14.7 \%$ for uveitis, $5.8 \%$ for IBD, $4.3 \%$ for dactylitis, and $9.0 \%$ for enthesitis (Table). The proportion with EAMs was: slightly higher among females versus males (31.0\% vs. $26.7 \%$ ), among older versus younger patients (29.5\% vs. $25.9 \%$ ), among those with more severe disease (from $29.2 \%$ [mild AS] vs. $34.1 \%$ [severe AS]), and among anti-TNF treated patients (18.8\% [anti-TNF-naïve] to $47.0 \%$ [treated with anti-TNFs, with switching]).

Table 1. EAMs among Canadian patients with AS from the Rhumadata dataset; overall, and according to levels of treatment status, key clinical, and demographic characteristics

\begin{tabular}{|c|c|c|c|c|c|c|c|c|c|c|c|}
\hline & \multirow[t]{2}{*}{$\mathrm{N}$} & \multicolumn{2}{|c|}{ Uveitis } & \multicolumn{2}{|c|}{ IBD } & \multicolumn{2}{|c|}{ Dactylitis } & \multicolumn{2}{|c|}{ Enthesitis } & \multicolumn{2}{|c|}{ Any EAM } \\
\hline & & $\mathrm{n}$ & $\%$ & $\bar{n}$ & $\%$ & $\mathrm{n}$ & $\%$ & $\mathrm{n}$ & $\%$ & $\mathrm{n}$ & $\%$ \\
\hline \multicolumn{12}{|l|}{ Overall } \\
\hline $\mathrm{N}$ & & & 14.7 & & 5.8 & & 4.3 & & 9.0 & & 28.4 \\
\hline Males & 566 & 81 & 14.3 & 29 & 5.1 & 23 & 4.1 & 47 & 8.3 & 151 & 26.7 \\
\hline Females & 378 & 58 & 15.3 & 26 & 6.9 & 18 & 4.8 & 38 & 10.1 & 117 & 31.0 \\
\hline$\leq 40$ years at cohort entry & 651 & 111 & 17.1 & 37 & 5.7 & 29 & 4.5 & 58 & 8.9 & 192 & 29.5 \\
\hline$>40$ years at cohort entry & 293 & 28 & 9.6 & 18 & 6.1 & 12 & 4.1 & 27 & 9.2 & 76 & 25.9 \\
\hline Missing AS severity & 166 & 12 & 7.2 & 7 & 4.2 & 2 & 1.2 & 3 & 1.8 & 21 & 12.7 \\
\hline Mild AS (BASDAI <3.5) & 271 & 47 & 17.3 & 16 & 5.9 & 12 & 4.4 & 21 & 7.7 & 79 & 29.2 \\
\hline \multicolumn{12}{|l|}{ Moderate AS } \\
\hline$(3.5 \leq$ BASDAI $<6$. & 252 & 44 & 17.5 & 12 & 4.8 & 13 & 5.2 & 26 & 10.3 & 81 & 32.1 \\
\hline Severe A $\bar{S}($ BASDAI $\geq 6.0$ ) & 255 & 36 & 14.1 & 20 & 7.8 & 14 & 5.5 & 35 & 13.7 & 87 & 34.1 \\
\hline Anti-TNF naïve & 490 & 47 & 9.6 & 18 & 3.7 & 11 & 2.2 & 25 & 5.1 & 92 & 18.8 \\
\hline \multicolumn{12}{|l|}{ Anti-TNF treated } \\
\hline [no switching] & 286 & 51 & 17.8 & 21 & 7.3 & 15 & 5.2 & 28 & 9.8 & 97 & 33.9 \\
\hline \multicolumn{12}{|l|}{ Anti-TNF treated } \\
\hline [with & 168 & 41 & 24.4 & 16 & 9.5 & 15 & 8.9 & 32 & 19.0 & 79 & 47.0 \\
\hline
\end{tabular}

Conclusions: EAMs are common among Canadians with AS, occurring in up to $28 \%$ over almost 10 years of follow-up, with uveitis occurring the most frequently (in almost $15 \%$ of the cohort). EAMs were most frequent among those with more severe disease (in 34\%) and among those treated with anti-TNFs (in 20-50\% of such patients). These estimates are useful for comparing to other geographic areas, where the risk factor distribution for AS and its sequelae would differ; and for use in economic models to evaluate the benefits and costs of new therapies. Disclosure of Interest: S. Szabo: None declared, S. Chehab Employee of: Novartis Canada, L. Coupal Consultant for: Novartis, Speakers bureau: Novartis, D. Choquette: None declared

DOI: 10.1136/annrheumdis-2017-eular.5021

\section{SAT0424 AXIAL DISEASE IN PSORIATIC ARTHRITIS: BURDEN OF UNDERDIAGNOSED DISEASE AND RISK FACTORS IN REAL LIFE}

S.Z. Aydin ${ }^{1}$, U. Kalyoncu ${ }^{2}$ on behalf of the PsART study group. ${ }^{1}$ University of Ottawa, Ottawa, Canada; ${ }^{2}$ Hacettepe University, Ankara, Turkey

Background: The frequency of axial disease in Psoriatic Arthritis (PsA) is around $24-78 \%$ with additional patients with subclinical disease who have spondylitic changes or sacroilitis in the absence of clinical findings. Despite that most of the physicians do not perform routine imaging with the argument that subclinical disease has no effects on management decisions.

Objectives: We aimed to explore barriers for diagnosing axial disease in PsA and its implications in real life.

Methods: PsART (Psoriatic Arthritis Registry of Iurkey) is a prospective, multicentre registry where PsA patients are consecutively recruited. Radiographs of the spine and sacroiliac joints were scored by one central reader, whenever available. Patients with axial disease according to the physician were compared with patients with imaging findings only and risk factors for being underdiagnosed were investigated.

Results: Among 1195 patients, $35 \%$ had axial disease according to the physician who were more frequently men $(41.2 \%$ vs $32.2 \%$; $p=0.04)$, younger $(44.4(12.2)$ vs 47.9 (13); $p<0.001)$, more frequently smokers ( $44.6 \%$ vs $34.1 \% ; p<0.001)$, more on anti TNFs (37.1\% vs $29.4 \% ; p=0.01)$ and had more nail involvement $(49.9 \%$ vs $43.2 \% ; \mathrm{p}=0.03)$. Within the IBP criteria, the ASAS criteria had the lowest sensitivity (59.7\%) which was even lower in women (53.1\%). Forty-nine (15.7\%) patients were classified as having axial disease according to the rheumatologist despite not fulfilling any of the IBP criteria which was more frequent for women $(21.1 \%)$ than men $(8.2 \%, p=0.002)$. Among 71 patients that had syndesmophytes, 20 patients $(28.2 \%)$ were not classified as having axial disease according to the physician. This was higher for women $(15 / 42,35.7 \%)$ then men $(5 / 29,17.2 \%)$. There were 126 patients who had sacroiliitis fulfilling the ASAS criteria, despite not being categorized as having axial disease by the clinician. The risk of being underdiagnosed was higher for women ( $30.8 \%$ vs $18.4 \% ; p=0.003)$. These patients had higher Leeds enthesitis scores, tender and swollen joint counts (table) and were less using anti-TNF medications (14.6\% vs $38.7 \%$; $p<0.001)$. The PROs and the physician global assessment were similar, suggesting a similar disease activity state according to the patients and physicians in diagnosed and underdiagnosed groups.

Table 1. Comparison of outcomes in patients with axial disease according to the clinician and axial disease by imaging only

\begin{tabular}{lccc}
\hline & $\begin{array}{c}\text { Axial disease according to } \\
\text { the Clinician }(\mathrm{n}=415)\end{array}$ & $\begin{array}{c}\text { Axial disease by } \\
\text { imaging only }(\mathrm{n}=126)\end{array}$ & $\mathrm{p}$ \\
\hline Patient global assessment & $47(24.8)$ & $49.2(20.8)$ & 0.4 \\
Pain & $46.4(28.7)$ & $50.1(23.3)$ & 0.3 \\
Fatigue & $47.1(27.7)$ & $51.9(23.6)$ & 0.1 \\
BASDAI & $4.5(2.5)$ & $3.9(2.3)$ & 0.08 \\
BASFI & $3.3(2.5)$ & $3.2(2.4)$ & 0.8 \\
Physician's global assessment & $38.7(23.3)$ & $41(18.9)$ & 0.2 \\
Tender joint count & $3.4(4.7)$ & $5.3(6)$ & $<0.001$ \\
Swollen joint count & $1.3(2.5)$ & $2(3)$ & $<0.001$ \\
Leeds enthesitis index & $0.3(0.8)$ & $0.4(1)$ & 0.05 \\
\hline
\end{tabular}

Conclusions: Underdiagnosed axial disease is frequent in PsA, women having higher risk and IBP criteria being less sensitive in women. More complex patients (eg with higher enthesitis and peripheral arthritis) have a higher risk of being underdiagnosed. These patients are less frequently treated with biologic treatments, which could be the right treatment choice if were diagnosed. Axial disease needs to be ruled out using imaging modalities, even if back pain does not clinically suggest an inflammatory pattern.

Disclosure of Interest: None declared

DOI: 10.1136/annrheumdis-2017-eular.3022

\section{SAT0425 SYMPTOMOLOGY, DISEASE STATUS, AND REMISSION RATES OF NON-RADIOGRAPHIC AXIAL SPONDYLOARTHRITIS AND ANKYLOSING SPONDYLITIS PATIENTS IN EUROPE}

T.M. Hunter ${ }^{1}$, D. Sandoval ${ }^{1}$, S. Lobosco ${ }^{2}$, R. Moon ${ }^{2}$, J. Birt ${ }^{1}$, G. Miligan ${ }^{2} .{ }^{1} E l i$ Lilly and Company, Indianapolis, United States; ${ }^{2}$ Adelphi Real World, Bollington, United Kingdom

Background: Axial Spondyloarthritis (axSpA) is a chronic inflammatory disease predominantly affecting the sacroiliac joints and spine. Ankylosing spondylitis (AS) and non-radiographic axSpA (nr-axSpA) have been considered to represent the same axial spondyloarthritis disorder, but are differentiated by the presence or absence of structural changes in the sacroiliac joints as determined by common imaging modalities.

Objectives: To better understand the symptoms and clinical characteristics of $\mathrm{nr}$-axSpA patients and how they compare to ankylosing spondylitis patients in Europe.

Methods: Data drom the 2015 SpA Disease Specific Programme, a crosssectional, multi-national survey of patients and rheumatologists conducted in France, Germany, Italy, Spain, and the UNited Kingdom were analyzed. Rheumatologists $(n=299)$ completed forms containing patient demographics, clinical results and symptomology. Symptoms, disease activity, and disease status (defined as improving, stable, unstable, deteriorating) of AS and nr-axSpA patients were compared.

Results: A total of 3,033 patients (AS: 1,$520 ; n r-a x S p A: 1,513)$ were included in the analysis. A higher proportion of AS patients were male ( $72 \%$ vs. $53 \%)$, older (mean age $=44.8$ vs. 41.0 ), had a higher BMl and were employed when compared to $\mathrm{nr}$-axSpA patients. Nr-axSpA patients' current disease status was less likely to be stable $(p<0.0001)$ in comparison to AS patients. Nr-axSpA patients were also less likely to be in remission $(p<0.0001)$. Nr-axSpA patients were reported as having higher pain level $(p=0.0333)$ than AS patients. AS patients had more axSpA symptoms, such as spinal fusion and loss of movement, however nr-axSpA patients were more likely to have inflammatory back pain, enthesitis, persistent lower back pain, and nocturnal wakening.

Conclusions: Both nr-axSpA and AS appear to have many similar clinical characteristics with few distinct features between them. However, in spite of these similarities, nr-axSpA patients show less stability and a lower likelihood of remission when compared to AS patients. These findings may suggest that $\mathrm{nr}$-axSpA is as burdensome as AS, and that both conditions may warrant similar treatment approaches from an early stage.

Disclosure of Interest: T. Hunter Employee of: Eli Lilly and Company, D. Sandoval Employee of: Eli Lilly and Company, S. Lobosco Employee of: Adelphi Real World, R. Moon Employee of: Adelphi Real World, J. Birt Employee of: Eli Lilly and Company, G. Miligan Employee of: Adelphi Real World

DOI: 10.1136/annrheumdis-2017-eular.2956 